\title{
Research and Practice of Bilingual Teaching Reform in Frontier Research of Functional Analysis
}

\author{
Hongkui $\mathrm{Li}^{1, *}$, Wenling Zhao ${ }^{2}$ \\ ${ }^{1}$ School of Mathematics and Statistics, Shandong University of Technology \\ Zibo, China \\ ${ }^{2}$ School of Mathematics and Statistics, Shandong University of Technology \\ Zibo, China \\ *Corresponding author's email: lhk8068 [AT] 163.com
}

\begin{abstract}
This paper introduces the research and practice of the frontier bilingual teaching reform of functional analysis, an innovative project of Shandong University of Technology. Firstly, the functional analysis is introduced, the problems to be solved in this research are put forward and the significance of reform research is discussed. Secondly, the contents and objectives of this project are arranged. Finally, the specific implementation scheme and time schedule are given.
\end{abstract}

Keywords-Bilingual reaching reform, Functional analysis, Teaching reform research

\section{INTRODUCTION}

\subsection{Problems to be Solved}

The functional analysis theory is an analytic mathematics that studies the functional and operator theory in infinite dimensional vector space by using the viewpoint of analysis, geometry and algebra. It originates from some variational and boundary problems in classical mathematical physics, and generalizes many important results in classical analysis and functional theory. As an important branch of modern mathematics, functional analysis has become a comprehensive and rich subject in the mid-20th century. Its interaction with other disciplines, in the process of its development, not only have important applications in geometry, topology, differential equations, computational mathematics, optimization theory and other branches of mathematics, but also widely used in continuum mechanics, quantum field theory and engineering technology and other fields. Functional analysis has been referred to as "Twentieth Century calculus" by modern scientific community". In view of its importance, the course of functional analysis theory has naturally become one of the basic courses for graduate students in contemporary mathematics. In fact, since the 50s of last century, functional analysis has been a very important course for students majoring in mathematics. Functional analysis, abstract algebra, topology are called the "new three basic courses of mathematics". Today it is not only offered in the teaching of basic mathematics in the Department of mathematics at various universities, but also in the teaching of Applied Mathematics, information and Computing Science in many schools. In addition, some senior undergraduate students and graduate students also offer this course at home and abroad. First, functional analysis, a very important professional basic course for postgraduates of mathematics in colleges and universities, its theory is very profound and highly abstract, which makes students generally feel difficulty in learning and abstract. Secondly, in recent years, with the continuous expansion of graduate enrollment, enrollment increased level difference students, and fewer hours and more contents, it is difficult for students to understand the content and grasp the key content which also bring difficulties in the teaching of the course. Finally, no fixed teaching mode is available, so how to efficiently conduct functional analysis to explain the theoretical knowledge and the training courses for postgraduates' scientific research innovation ability has become an urgent problem to consider teachers.

At present, more authoritative international functional analysis reference books mainly include the following [1-3]: Real and complex analysis, A course in functional analysis and Introduction to Functional Analysis. These books are classical and profound. They are essential books for postgraduates and applied researchers in mathematics. Note that these reference books are books in foreign language teaching and learning, the study of functional analysis must let the Chinese students grasp the English expression of functional analysis theory, have the ability of independent reading and writing of the theory of functional analysis in English. So it requires us to explore the reform of bilingual teaching, and many colleges and universities are already doing it [4-13]. 
In order to enable students to grasp the basic nature and structure of functional analysis, and to train students' English writing and expression, and to learn the thinking mode of functional analysis theory, it requires the teachers to organize carefully, grasping the application in other disciplines in the research of functional analysis and giving lessons in a bilingual manner in the teaching of functional analysis. Then, passively taught by the teacher become acquire knowledge autonomously and carry out the preliminary theoretical or practical innovation.

\subsection{Research Significance}

For graduate students, master the basic knowledge of the professional knowledge is the most basic work. Besides, it is important for students to complete a certain research work and master's degree thesis. Through the functional analysis of bilingual teaching research type, introduction and functional analysis application research frontier and hot research related knowledge properly, can not only strengthen the students' understanding of the importance of the course, but also can improve the students' learning interest of the courses, reinforcement learning autonomy, improve the efficiency of learning. So the students can grasp the theory, the methods of functional analysis, the basic theory and study of functional analysis, capable of independent reading academic journals at home and abroad related research and functional analysis in foreign academic achievements. In the international and domestic academic conferences, we can learn and communicate with the experts in related fields smoothly, and enter the academic front in a relatively short time. So as to lay a solid foundation for the future development of their own.

\subsection{Domestic and Foreign Research Status}

At present, the domestic and foreign research "functional analysis" textbook selection courses generally have three situations [14-17]: one is directly using foreign classic textbook (GTM Series), such as the famous scientist Rudin (Walter Rudin) analysis of the "functional analysis". These textbooks are classic and profound, which is mostly used by foreign universities and key universities in China. Another kind is the classic textbooks compiled by famous scholars in China, such as Functional Analysis (edited by Zhang Gongqing), the Real Function and Functional Analysis (edited by Xia Daohang et al), the Basis of Real Variable Function and Functional Analysis (edited by Cheng Qixiang et al), the Foundation of Functional Analysis (edited by Liu Peide). Each of these textbooks has its own characteristics and has been widely used for many years, and it is suitable for students who have good foundation and their classes are more substantial. The last one is the recent publication of many engineering colleges by application of "functional analysis". The contents are concise, practical, but lack of mathematical rigor. These books are suitable for engineering graduate students, but not suitable for the study of mathematics major students. In recent years, Yunnan University has proposed that in the course of graduate functional analysis teaching, we should appropriately introduce the research frontier and the hot research knowledge related to the application of functional analysis.

\section{METHODOLOGY}

\subsection{Organize Carefully and Pay Attention to the Principal Line}

In order to grasp the advanced research of functional analysis at any time, the teachers need to study functional analysis as a tool; at the same time, keeping abreast of research trends throughout mathematics, to master the application in other disciplines in functional analysis. The main purpose of teaching is to transfer knowledge, and the main purpose of scientific research is to create knowledge. These two are not contradictory, they promote each other. The results of scientific research, scientific research methods, and certain teaching designs are passed by the teachers to the students, so that the teaching quality can be improved. The teacher imparts the research frontier knowledge to the student, needs to elaborate to the teaching process. The frontiers of knowledge often use functional deep analysis of knowledge as a tool for functional analysis of the course of beginner students, is still unable to understand the knowledge, which requires teachers to refine appropriate knowledge, designed to solve the problem of mode, its process is as follows: ask questions, analyze problems, to solve the problem and rational induction.

In the research combined with the teaching process, the following two points needed to pay attention to: one is to draw a clear distinction between primary and secondary, we should give priority to teaching basic knowledge and not take too much time to teach frontier knowledge. The other is that the research frontiers of knowledge should be introduced widely. Functional analysis, a basic course, is set up in the first semester, students have not grasp the main knowledge of a specific mathematical research direction, the detailed introduction for a specific problem makes students difficult to understand due to lack of professional knowledge.

\subsection{Textbook Selection}

According to the quality of freshmen student, select the A course in functional analysis as the basic materials, this book is the mainstream textbook of functional analysis, and we can also get some enlightening interpretations from the textbook. Then selected Zhang Gongqing's textbook functional analysis, this book is concise, the spectral theory of Hilbert space and the three theorems are clearer than other textbooks, it also includes the classical application of 
functional analysis in other mathematics subjects.

\subsection{Formulating the Reform Plan of Research Frontier Bilingual Teaching}

The teachers explain the knowledge of the basic functional analysis textbooks for postgraduates combined with the frontiers of knowledge in a bilingual way, after class, some small thinking topics are reserved for students to think. Set aside a fraction of the time, report teaching content they are interested in by the students with bilingual way.

\subsection{Instructional Objective}

After learning, students should have the following abilities:

(1) Students should master the basic knowledge and basic methods of functional analysis, and know the application of functional analysis knowledge in mathematics specialty.

(2) To improve the students' ability to grasp the whole course of functional analysis.

(3) Students are able to find and solve the forward application problems of functional analysis and functional analysis in related fields independently, and are able to write foreign language papers fluently

\section{PROJECT IMPLEMENTATION CONDITIONS}

(1) The project leader has taught academic degree and master's graduate course functional analysis for a number of graduate students since 2007, has accumulated a wealth of teaching experience and materials for preparing lessons.

(2) Course teaching of Functional Analysis has been using the original English textbook A course in functional analysis, which has laid a good foundation for the implementation of this project.

(3) The project team has collected most of the classic teaching materials of functional analysis at home and abroad, which provides a powerful guarantee for the selection of the teaching materials of this project.

(4) All the members of the project team have a doctorate, and engaged in teaching front-line jobs, familiar with functional analysis and its application of theoretical knowledge and teaching methods.

(5) The teacher, researching in functional analysis and nonlinear systems, familiar with the bilingual teaching mode of teaching content of functional analysis and research, able to grasp the dynamic research of functional analysis accurately and its application, which provide a strong guarantee for students' independent research.

\section{IMPLEMENTATION PLAN AND SCHEDULE}

(1) February 2017 to August 2017

To select teaching materials and to develop initial teaching program.

(2) September 2017 to January 2018

According to the selected teaching materials and the teaching program, the functional analysis is conducted by the teaching staff to study the cutting-edge bilingual teaching. To provide students with functional analysis and its application problems, and to lead students to conduct independent research activities.

(3) February 2018 to August 2018

To summarize the teaching methods of the last semester, solve the problems encountered in teaching, and improve the teaching program.

(4) September 2018 to January 2019

According to the selected teaching materials and the teaching plan, the functional analysis is conducted by the teaching teacher with the cutting-edge bilingual teaching. Besides, teachers should organize previous students to exchange experience with the current students regularly, and instruct students to write foreign language papers.

\section{EXPECTED RESULTS, PRACTICAL IMPLICATIONS AND APPLICATION VALUE}

(1) To explore and summarize the Research and practice of bilingual teaching reform in frontier research of functional analysis.

(2) To popularize the reform program to the teaching practice of other courses, such as linear system, convex analysis.

(3) To guide students to carry out scientific research practice of functional analysis and its application. It is expected 
that 3 academic papers will be published by SCI or EI during the period from June 2017 to January 2019.

\section{ACKNOWLEDGEMENT}

This work is supported by Doctoral Fund of Shandong University of Technology of China (4041/415061), Comprehensive budget management system design (9101/215043), Shandong Research project of teaching reform in undergraduate colleges and universities of China (2015Z071).

This work is supported by Open Project Foundation of Intelligent Information Processing Key Laboratory of Shanxi Province (2017003).

\section{REFERENCES}

[1] Rudin W., Real and complex analysis[M]. Tata McGraw-Hill Education, 1987.

[2] Conway J B., A course in functional analysis[M]. Springer, 1990.

[3] Taylor A E., Introduction to Functional Analysis[M]. John Wiley and Sons Ltd, 1980.

[4] Cheng-Yue L I. Design and Practice in Bilingual Teaching of Functional Analysis for Minority Undergraduates[J]. Journal of Minzu University of China, 2013.

[5] Gua M H, Haob J Y. Study of Bilingual Teaching Reform and Practice Based on Web Resources[C]. Advances in Computer Science, Environment, Ecoinformatics, and Education - International Conference, Csee 2011, Wuhan, China, August 21-22, 2011. Proceedings. DBLP, 2011:372-375.

[6] Kang Z, Wang R, Wang Y. Bilingual Teaching Reform and Practice of Engineering Student's "Professional Foreign Language" Based on Multimedia Technology[J]. 2011, 218:570-575.

[7] Shao yuan X U, Hong G S, Jiang X H, et al. The Investigation and Practice of Bilingual Teaching of the Major Courses for the Mathematical Graduates[J]. Journal of Huaibei Coal Industry Teachers College, 2009.

[8] Zhao L. Bilingual Teaching Reform Ideas of International Business from Experience of Visiting US Classroom Teaching[J]. 2015.

[9] Wang J, Deng K, Weng L, et al. Further Exploration of the Bilingual Teaching Reform of "Biological Science"[J]. 2015.

[10] Song X, Yang J, Liu W, et al. The Exploration of Bilingual Teaching Reform in Medical Immunology Experiment Course[J]. China Continuing Medical Education, 2016.

[11] Gong S. Discussion on Bilingual Teaching Reform of Remote Sensing Principles and Applications Course[J]. Geospatial Information, 2016.

[12] Hong S R. Practice and Thinking of Reform of Bilingual Teaching in Plant Tissue Culture from the Perspective of the Cultivation of Excellent Talents in Agriculture and Forestry[J]. Heilongjiang Agricultural Sciences, 2016.

[13] Fang Gao, Mark S.K. Shum. Investigating the role of bilingual teaching assistants in Hong Kong: an exploratory study[J]. Educational Research, 2010, 52(4):445-456.

[14] Conway J B. A course in functional analysis. 2nd ed.[J]. 2003.

[15] Eidelman Y, Milman V, Tsolomitis A. Functional Analysis: An Introduction[J]. Siam Review, $2005,33(3): 322$.

[16] Stein E M, Shakarchi R. Functional analysis. Introduction to further topics in analysis[J]. 2011, 723(2):L243-L247.

[17] Kuang J C. On Research and Practice of Reform Textbook and Teaching Method in Real Analysis and Functional Analysis[J]. Journal of Mathematics Education, 2001, 8(2). 